\title{
Social and Spatial Structures of Innovation in the Irish Animation Industry
}

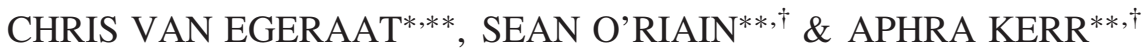 \\ *Department of Geography, National University of Ireland, Maynooth, Ireland, ${ }^{* *}$ National Institute for \\ Regional and Spatial Analysis, Maynooth, Ireland, ${ }^{\dagger}$ Department of Sociology, National University of Ireland, \\ Maynooth, Ireland
}

(Received June 2012; accepted August 2012)

\begin{abstract}
This paper assesses the relevance of the knowledge base conceptualization and the relationship between the symbolic knowledge base and the spatiality of knowledge flow in the context of the animation industry in Ireland. The paper draws on findings from a study of four innovation case studies. In broad terms, the findings provide further support for the applicability of the knowledge base approach and the association of the animation industry with the symbolic knowledge base. However, in relation to the spatiality of knowledge flows, the findings contradict the theoretically deduced postulations. Nearly all of the knowledge sources are located overseas. In addition, the study finds little support for the role of local buzz in knowledge flow. The local animation community "buzzes globally" at international events.
\end{abstract}

\section{Introduction}

Analysts have emphasized for some time that learning and innovation by firms occur within a broader "system of innovation"- the network of inter-firm relations, public institutions, occupational communities and other actors that surround any firm (Lundvall, 1992; Saxenian, 1994, 2006). Typically, the emphasis has been on how these systems of innovation differ between nations (Kim \& Nelson, 2000; Lundvall et al., 2002). Another body of research has demonstrated the importance of "sectoral systems of innovation" in shaping innovation and growth, particularly in a "knowledge economy" (Kim \& Nelson, 2000; Lundvall et al., 2002; Malerba, 2005). Much technological learning occurs around specific products (Storper, 1997) and this "product-based technological learning" becomes the basis of sectoral systems. The key products within a sector become the focus of learning among a diverse group of economic actors-firms, workers, academics,

Correspondence Address: Chris van Egeraat, Department of Geography, National University of Ireland, Maynooth, Ireland. Email: chris.vanegeraat@nuim.ie 
researchers, policy-makers and others. These become the crucial constitutive elements of "business ecosystems", facilitating and shaping knowledge flows.

The social aspects of innovation are crucially embedded in the spatial organization of knowledge flow and innovation. Sectoral and national systems of innovation interact and potentially complement each other-Michael Porter's conceptualization of "clusters" is one attempt to explain economic growth through a focus on how sectoral and national institutions interlock to create virtuous circles of industrial development (see also Hollingsworth et al., 1994; Kitschelt, 1991). Contributions to a knowledge based theory of spatial clustering typically interpret learning and innovation as interactive processes that involve an exchange of knowledge between firms and other actors. The idea is that proximity in local clusters can lead to dense networks of communication and information linkages that support knowledge flows.

Although remaining highly influential, these ideas are increasingly challenged by empirical studies that show that firms in even the most developed clusters are often highly depended on non-local relations for their knowledge. Recent contributions to the knowledge based theory of spatial clustering specifically incorporate the idea that firms in clusters depend on both local and non-local knowledge flows through "local buzz" and "global pipelines" (Bathelt et al., 2004; Gertler \& Wolfe, 2006). This constitutes a move to a more complex view of a multi-scalar geography of knowledge and local clusters as nodes in global networks.

More recently, the knowledge base approach suggest that the analysis of the sociospatial structures of innovation and knowledge flow needs to be sensitive to the knowledge base involved. A distinction is made between "synthetic", "analytical" and "symbolic" knowledge bases (Asheim et al., 2007, 2011; Gertler, 2008). The proponents suggest that the different knowledge bases are characterized by different sensitivities to geographical distance in relation to knowledge flow. Industries drawing on the symbolic knowledge base are believed to be most sensitive to geographical distance in relation to knowledge exchange.

This paper assesses the relevance of the knowledge base conceptualization and the relationship between the symbolic knowledge base and the spatiality of knowledge flow in the context of the animation industry in Ireland. The paper draws on findings from a study of four innovation case studies. The paper begins with an outline of the knowledge base approach and a review of the literature on the role of proximity in innovation and knowledge flow. This is followed by a description of the methodology. The next section presents an illustrative case, providing an overview of the different stages of an animated television series innovation project. Following this, we examine the extent to which the various stages in the innovation trajectory portray characteristics of the symbolic knowledge base. This is followed, successively, by an account of the main sources of knowledge and an examination of their location, building on the theoretical discussion in the "Knowledge bases and proximity" section. Finally, some conclusions are drawn from the foregoing analysis.

\section{Knowledge Bases and Proximity}

The premise of the study is that there are varying pathways to successful innovation and that the socio-spatial structures underlying these pathways vary by the industrial sector. To understand the social and spatial patterns of knowledge flows and innovation, we need to 
be sensitive to the type of knowledge involved. Asheim and Gertler (2005) have criticized Polanyi's (1967) binary distinction between codified and tacit knowledge for a narrow understanding of knowledge and innovation. This led to a conceptualization of different types of "knowledge bases" that are used in innovation processes. A distinction is made between "synthetic", "analytical" and "symbolic" knowledge bases (Asheim et al., 2007, 2011). This distinction takes account of the rationale for knowledge creation, the criteria for successful outcomes, the strategies of turning knowledge into innovation and the interplay between the actors involved. The categories entail different mixes of tacit and codified knowledge, qualifications and skills required by organizations, as well as specific innovation challenges and pressures. The typology encompasses the diversity of professional and occupational groups.

An analytical knowledge base refers to activities where scientific knowledge based on formal models and codification is highly important. ${ }^{1}$ Knowledge inputs and outputs are often about developing new knowledge about natural systems by applying scientific laws- "know-why". Knowledge is often codified. University-industry links and networks are relatively important. The activities require specific qualifications. In particular, analytical skills, abstraction and theory building are often needed. The core of the workforce often needs some research experience or university training. Knowledge creation in the form of scientific discoveries and generic technological inventions is relatively important. Knowledge application is in the form of new products and processes.

A synthetic knowledge base refers to activities where innovation takes place mainly through the application or novel combinations of existing knowledge. Often this occurs in response to the need to solve specific problems identified during the interaction with customers and suppliers. Products are often one-off or produced in small series. R\&D, especially the research element, is generally less important than in the analytical knowledge base. University-industry links are sometimes relevant but primarily in the field of applied research and development. Knowledge is often created in an inductive process of experimentation or through practical work. Knowledge output can be partially codified but tacit knowledge is more prevalent than in the analytical knowledge base, in particular, due to the fact that knowledge often results from experience gained at the workplace and through learning by doing. There is a relatively high requirement of concrete "know-how" and practical skills often provided by on-the-job training. Innovation tends to be an incremental process, dominated by the modification of existing products or processes.

The proponents relate symbolic knowledge to the aesthetic attributes of products, to the creation of designs and images and the economic use of various forms of cultural artefacts. This type of knowledge is considered particularly relevant to "cultural industries" such as media. An important part of the innovation in these industries takes the form of the "creation" of new ideas and images, rather than new physical production processes. Symbolic knowledge may be embedded in tangible goods but its economic value arises from its intangible character. In the cultural industries, in particular, the input is aesthetic rather than cognitive in quality. The knowledge involved is incorporated and transmitted in aesthetic symbols, images and narratives with strong semiotic knowledge content. This type of knowledge is often narrowly tied to a deep understanding of the habits and norms and "everyday culture" of specific social groupings. Due to the cultural embeddedness of interpretations, this type of knowledge base is characterized by a distinctive tacit component and is often highly context-specific. The acquisition of skills is less tied to 
formal qualifications and university degrees than to practice in various stages of the creative process. The process of socialization (rather than formal education) in the trade is not only important with regard to training "know-how", but also for acquiring "know-who", that is knowledge of potential collaborators.

The proponents stress that the three-fold distinction outlined above refers to ideal types and that most activities are in practice comprised of more than one knowledge base. Innovation projects often involve actors from different industries with different knowledge base characteristics. This has been convincingly illustrated by the micro-scale studies conducted by Moodysson et al. (2008). Here, the focus is on the "mode of knowledge creation"- the characteristics of the actual knowledge creation activities and knowledge interactions-in specific innovation processes, within one particular industry. This allows for a concrete investigation of how the different modes are integrated in concrete innovation projects. The case-study findings show that different modes of knowledge creation are present in different phases of innovation processes, but with different intensity, and different outcomes for the spatiality of the knowledge flows. Even at the activity level, it is not possible to characterize activities as either analytical or synthetic. However, in most cases, the authors were able to clearly identify a dominant mode of knowledge creation in the different activities.

The knowledge base conceptualization implies that different industries are characterized by different social-spatial conditions and pathways to innovation. In relation to space, the proponents suggest that the different knowledge bases are characterized by different sensitivities to geographical distance in relation to knowledge flow (Asheim et al., 2007; Gertler, 2008). Industries drawing on the symbolic knowledge base are believed to be most sensitive to geographical distance in relation to knowledge exchange. "Know-who" type of knowledge is augmented through large gatherings which require face-to-face contacts. In addition, the craft-production nature of the innovation process and the tacit nature of the know-how call for a high amount of face-to-face communication. Finally, Martin and Moodysson (2011) stress the context-specific nature of the symbolic knowledge. This means that the absorptive capacity of the actors involved in the exchange is highly localized, embedded in the location.

Initial studies applying the knowledge base conceptualization have found support for the knowledge base conceptualization and the hypothesized relationship between knowledge bases and the spatiality of knowledge flow. Most of these studies have focussed on examples of analytical and synthetic knowledge bases (Moodysson et al., 2008; see also Gertler, 2008). Martin and Moodysson (2011) were amongst the first to apply the framework in the context of a symbolic industry - the moving media industry in Southern Sweden. The moving media industry covers a range of activities from traditional film and broadcasting to digital design and computer games software. The authors find support for the theoretical link between the symbolic knowledge base and the organizational and spatial patterns of knowledge sourcing.

The authors captured knowledge flows from three different angles: "monitoring" (knowledge sourcing through intermediaries), "mobility" (exchange of knowledge via mobility of key employees) and "collaboration" (direct interaction between actors). As regards monitoring, they found that less formalized knowledge sources such as fairs and the Internet are more important than surveys and journals representing scientific knowledge. In relation to mobility, the firms in the industry recruit key employees primarily from organizations in the same region. Finally, as regards to collaboration, 
intra-regional knowledge exchange is prevailing. These findings need to be tested by other studies, notably in different contexts.

In conducting such studies, an understanding of the relative importance of local and global knowledge flows in knowledge creation and innovation and the extent to which different flows are sensitive to proximity is facilitated by distinguishing between different modes of knowledge exchange, different dimensions of proximity and different levels of intentionality of knowledge exchange.

As regards modes of knowledge exchange, knowledge can be exchanged using different modes or media, including face-to-face, post, telephone, email, video-conferencing, Internet and intranet forums. Geographical proximity tends to be related to the requirement of face-to-face communication between actors. Clearly, innovations in communication technology have reduced the need for face-to-face contact in the exchange of knowledge, even in the context of detailed technical design issues (Mckinnon, 1997; Torre \& Rallet, 2005; Van Egeraat \& Jacobson, 2006). In addition, where face-to-face contact is required, the number of contact occasions can be very limited and/or involve short periods that can often be satisfied via frequent long-distance travel and the seconding of research staff for extended periods of time (Arita \& McCann, 2000; Torre \& Rallet, 2005; Van Egeraat \& Jacobson, 2006). ${ }^{2}$

In addition, various forms of relational proximity can act as substitutes for geographical proximity and facilitate knowledge flow and distanciated learning in distributed teams (Boschma, 2005; Gertler, 2008; Moodysson, 2007; Torre \& Gilly, 2000; Torre \& Rallet, 2005). Boschma (2005) applies a comprehensive categorization involving cognitive proximity (proximity in knowledge base and expertise), organizational proximity (the extent to which relations are shared in an organizational arrangement), social proximity (in terms of socially embedded relations between agents at the micro-level) and institutional proximity (related to both economic actors sharing the same institutional rules and a set of cultural habits and values). All these forms of proximity can facilitate interactive learning and innovation. On the other hand, geographical proximity may facilitate knowledge flow, but it is not a sufficient condition because knowledge flow and learning require at least cognitive proximity and, in most cases, a combination of dimensions is at play. Although the meaning and value associated with symbolic knowledge may be particularly difficult to communicate in distributed teams (Martin \& Moodysson, 2011), even here the issue may be overcome through various forms of relational proximity, notably cultural proximity.

As regards intentionality, we distinguish between intentional and unintentional knowledge flows and learning. Unintentional flows (Oerlemans \& Meeus, 2005) within a group of actors involve the acts of observation and comparison (Malmberg \& Maskell, 2002). These unintentional flows and spillovers are important for know-who and inspiration type knowledge — critical elements of the symbolic knowledge base. They are believed to be particularly sensitive to proximity, both geographical and non-geographical. Social, cultural and institutional proximity are believed to be especially important for unintentional knowledge flow. Geographical proximity is believed to be important because much (though not all) unintentional knowledge flow occurs during face-to-face events and because the non-geographical forms of proximity are augmented by geographical proximity.

The intentional vs. unintentional knowledge flow distinction is closely related to the concept of "buzz" (Bathelt et al., 2004; Gertler, 2008; Gertler \& Wolfe, 2006; Moodysson, 
2008; Storper \& Venables, 2004). Asheim et al. (2006) argue that buzz has been defined in rather ambiguous ways and call for a more precise definition, distinguishing between buzz and face-to-face communication. As such, they present it as a different mode of communication (distinct from the face-to-face mode) and knowledge exchange. This may also be problematic since the authors also make the point that buzz is more efficiently transmitted in face-to-face contexts, thereby creating an overlap between the categories of modes of communication. We here define buzz based on the level of intentionality. "Buzz refers to non-deliberate knowledge and information exchange propensities" (Asheim et al., 2006, p. 214) and "is predominantly about knowledge spillovers" (Asheim et al., 2006, p. 216).

The concept of "buzz" has been contrasted to that of "global pipelines" (Bathelt et al., 2004). However, such conceptualization is problematic in capturing knowledge flows. Asheim et al. (2007) point out that buzz can be both local and global and can involve both electronic and face-to-face communication.

This paper assesses the relevance of the knowledge base conceptualization and the relationship between the symbolic knowledge base and the spatiality of knowledge flow in the context of the animation industry in Ireland. As a part of the broader media industries, the animation industry is generally associated with the symbolic knowledge base (Asheim et al., 2006). The only existing study focussing on the symbolic knowledge base investigated the case of the moving media industry in Southern Sweden (Martin \& Moodysson, 2011). One of the contributions of the current study, therefore, is to investigate these issues in a different context, notably in a country with different cultural links.

In addition, the current study has a different focus and methodology (see next section). Martin and Moodysson (2011) adopt an aggregate approach to analysing the extent and geography of knowledge networks and flows - the unit of analysis is the industry. The current study traces the knowledge flows of individual innovation projects- the unit of analysis is the innovation project. This allows for an analysis of the salience of different knowledge bases during the various phases of an innovation project. It also provides a different insight into the relevance of local vs. non-local knowledge flows and networks. On the basis of mapping the location of all collaborating partners (in an unidentified period) connected to the firms in the local cluster, Martin and Moodysson (2011) conclude that intra-regional knowledge exchange is prevailing. However, such aggregates do not inform us about the relative role of local partners for individual innovation projects, or the frequency of face-to-face contact.

\section{Methodology}

The study involved a multiple-case research design with four ${ }^{3}$ case studies serving a literal replication logic (Yin, 2003). The unit of analysis was the individual innovation project. Project selection was based on a review of secondary material and six initial interviews with industry experts in the Irish industry. This provided an overview of the sector as well as a list of companies, but we had no "universe" of projects. Instead, we used the list of companies to steer the case-study selection, which was strongly informed by the opinion of the industry experts. One of the selection criteria was that the project should be in an advanced stage, preferably already on the market.

Four animation projects were selected for study, all involving small-to-medium sized Irish enterprises. The case-studies took the form of "innovation biographies" - in-depth 
micro-studies tracing back the history/genealogy of particular innovations. The research team wished to see how the social-spatial relations of innovation vary throughout the innovation process. We therefore started with the innovation itself and explored how the innovation emerged over time. The Irish animation industry was a suitable case for study. It has incorporated global linkages from early in its history and has a stronger record in innovation in Ireland than other-related industries (e.g. games and other segments of the software industry). From the early establishment of Sullivan Bluth Studios in 1985 to recent international awards (including two Oscars), production and innovation in the local industry has been entangled in global connections. Taken together, the innovation biographies gave us a picture of the particular "innovation coalitions" that underpin innovation processes and outcomes. This allows us to "map" the actors (including firms, workers, firm networks, person-to-person networks, technical communities, universities and other institutions) that are involved in the innovation process at different stages, as well as to see how they interact with each other and how their boundaries shift and change over time. This will therefore allow us to examine how firms and other actors relate to one another at different stages of the innovation process. It also allows for an examination of the shifting spatialities of the process.

Fourteen interviews were conducted with staff from relevant companies and other institutions in Ireland. All interviews were recorded, transcribed and coded for the analysis. Interview data were supplemented and triangulated with information from secondary sources, notably annual reports, journals and Internet sites.

\section{The Animation Innovation Process: An Illustrative Case}

We explain the stages of the animation innovation process through the case of an animated children's television series (40-60 episodes). The series is an original concept based around the antics of Kicko, a young animal that endeavours to learn martial arts. The innovation trajectory of a computer-animated television series includes four stages: development, pre-production, production and post-production.

The development stage is partly a creative (artistic) stage and partly about business development. Typically, a production company will identify a theme based on an existing book or original idea and prepare a synopsis, often containing drawings to help visualize the key points. A key element of development is securing finance and attracting clients (pre-sales) for the series. Kicko is based on the original ideas of one of the founders of KilAnim, a small Irish animation company. In 2002, the company decided to bring the show into development with the co-founder acting as an Executive Producer. The development stage focussed on finding new partners and securing the necessary finance. These activities were supported by artistic activities, mainly the development of a promotional trailer and first scripts. The Director was able to develop the trailer practically on his own.

After securing funds for initial development work, in 2003, the show was successfully pitched at an international trade fair. This created the necessary interest from TV channels and potential partners. Over a 3-year period, the show turned into a co-production involving KilAnim, a Dutch production/distribution company, an Irish post-production house (TeleEire) and a large international children's programme broadcaster. Although the show had been pre-sold to other TV channels worldwide, this broadcaster became a co-producer on the basis of being the largest investor. A US-based, licensing and merchandizing rights company invested to exploit the licensing rights. 
In 2005, with the finance in place, the project moved to the pre-production stage. Pre-production starts with the very creative stage of further developing the basic rules of the show. This included the concept of art work for characters and locations as well as developing ideas about what the show is about, the personality of the characters and so forth. Much of this work was done by KilAnim's Director in conjunction with US-based free-lance script writers/editors. This forms the basis for further, similarly artistic, pre-production activities involving script-writing, detailed character design, storyboard development and animatics. ${ }^{4}$

At this stage, script writing was outsourced to a number of US-based script-writers, co-ordinated by two script editors in New York. At the same time, KilAnim recruited 35 people for its in-house pre-production and production team involving a range of skills including, amongst others, story boarders, background artists, animators, lay-out people, editors, a voice director, an art director, an animation director, an assistant director, a production manager and a producer. Most of the team were employed for the duration (18 month) of the project. The idea was to use "Flash" technology during the pre-production and production stages, but KilAnim had no experience organizing a production pipeline based on "Flash". To solve this, the company approached a producer that had done similar work in a Canadian animation company. In addition, in order to obtain additional know how, a small amount of the pre-production activity was outsourced to the Canadian company as well. Some of the voice recordings took place at the studios of TeleEire.

With the pre-production for the first-episodes completed, the series goes into production. This stage involves relatively less creative (read artistic) work, turning the pre-production work into an actual movie. This work was contracted to two animation companies in the Philippines and Malaysia. The activities were tightly organized and controlled by KilAnim, who employed a production supervisor to oversee the project on-site. The Philippine and Malaysian animators typically produced several versions of an episode, integrating editorial comments from KilAnim.

Post-production, the final stage, involves editing the production work and creating the final episode by adding or perfecting additional effects such as sound and lighting. The editorial process involves several formal stages with the co-producers and main broadcasting clients providing their comments. Post-production activities were carried out at the studios of TeleEire, the Irish company with a core expertise in post-production. They worked collaboratively with KilAnim's Director, Producer, Executive Producer and Voice Director. The first episode was aired in 2007 on CBBC in the UK. By the time of reporting, the show had aired in 120 countries.

\section{Knowledge Bases in Animation}

This section discusses the extent to which the innovation trajectories possess characteristics of the different modes of knowledge creation and comments upon the relevance of the knowledge base conceptualization. In all four cases, the first stages are dominated by the symbolic mode of knowledge creation, although the level of this dominance diminishes with each stage. The core innovation lies in the concept of the story/characters, the quality of the animation and the scripts for the various episodes. It is about creating and designing new ideas, images, narrative and metaphors, including a brand. It is less about creating artefacts with a use value. Companies did exploit novel technologies for use in the production process, but the innovative element of the shows does not reside in the technology. 
Knowledge inputs are of an aesthetic nature and demand the ability of symbol interpretation. Important sources include the individual artist's imagination and existing symbols and images obtained from a broad range of sources. This is clearly illustrated by the initial brainstorming session in Case 2.

Both of the participants like Kung Fu so they tried to think [...] what is like Kung Fu and sort of Zen. Then they thought of the Ying Yang symbol and they thought about what else is black and white .... (Executive Producer Case 2)

All artists were encouraged to watch Kung Fu films. In addition, in all cases, the success of the creation depends, at least to some extent, on an understanding of children's habits and everyday culture.

As it turned out we were sort of noticing things like ... oh, the colour path we have here is nice and girls would like that, and the black and white action sequences work very well. [...] Boys love black—black and red seems to be their colour co-ordination. If you see their clothes, it is usually black and whites and reds. That is what boys seem to gravitate towards and girls are more pastel and so we had a very pastel colour scheme for the background. (Executive Producer Case 2)

The activities during the early stages rely strongly on tacit knowledge. Codified knowledge plays almost no part. The artists do not read academic science journals or magazines. "I am not sort of wired that way to understand the academic side of it" (Case 3). Knowhow, based on experience, is clearly more important than know-why and many activities contain a strong craft element. "Animation is like a craft. You almost need to do it, it is like carpentry" (Managing Director, Case 1). Most artists had enjoyed some form of animation-related schooling, typically vocational education or the international equivalent, but on-the-job training and experience are very important and specialization tends to occur only after education.

When Flash technology came out people started to animate on the Internet using Flash-people did it naturally. We weren't working with it in college or anything like that. It was just a program we got and that we continued to use. We realised, 'oh right, you can animate with this.' So we kept experimenting with it. [...] It was really just practice. (Executive Producer, Case 2)

Finally, firms strongly depend on external partners for sharing production costs, accessing additional sources of finance, cheap labour and complementary skills and the actors differ from project to project. Know-who type knowledge and reputation are therefore crucial, particularly during the development stage.

The early stages already contain elements of a synthetic knowledge base. First, the innovation trajectory is characterized by user-centred innovation and strong user-producer interaction. The broadcaster played an important role in the innovation process, commenting on the initial designs and providing ideas to make sure that the design would be suitable for the audience. Second, the skills base is heterogeneous, both intra-firm and inter-firm. The production involves a range of actors that have developed specific skills including modellers, animators, editors, producers and so forth. Most of the staff would 
have enjoyed a rather general animation course and would have specialized in a particular role during their career.

The salience of the symbolic knowledge base diminishes with each stage. Know-who type knowledge is really most important during the development and pre-development stages. In addition, the production and, particularly, the post-production stages are far less creative (i.e. artistic). Although the activities of the Korean animation studio certainly include creative elements, "it is very prescribed, in that there is very little room for creativity or input from [the animators]. It is basically an exercise in joining the dots" (Executive Producer, Case 1). The production stage is characterized by a combination of the symbolic and synthetic modes of knowledge creation, with the symbolic still having the upper hand.

The salience of the symbolic knowledge base is further reduced with the transition to the post-production stage and it is no longer dominant. There is no room for artistic creativity. Arguably, this fourth stage has as many characteristics of a synthetic as a symbolic knowledge base although the activities are still not aimed at creating functional artefacts with a use value. The post-production activities involve "synthesising" the various components (outcomes of the various activities) into an overall product. The activities have become more mechanical and totally process driven.

In broad terms, the findings present further support for the applicability of the synthetic, analytical and symbolic knowledge base conceptualization. A number of critical reflections are included in the concluding section. The findings also provide support for the association of the animation sector and the symbolic knowledge base although elements of the synthetic knowledge base are evident as well. In line with Moodysson et al. (2008), the cases studies support the idea that most activities are in practice comprised of more than one mode of knowledge creation and that different modes of knowledge creation are present in different stages of the innovation trajectory, with different intensities. It is actually quite difficult to identify an individual activity that is completely dominated by a single mode of knowledge creation. Even the activities that are most dependent on a single mode of knowledge creation can present some characteristics of another mode.

\section{Main Sources of Knowledge}

This section discusses the main knowledge sources during the various stages of the innovation trajectories in the animation industry. Not all partners are important sources of knowledge. We therefore start with an overview of all actors.

The animation industry is characterized by "open innovation" (Chesbrough, 2003) with all cases involving a substantial number of external actors. All four innovation trajectories start with small animation companies. The first stage is used to identify and forge partnerships with the main project partners including other animation companies, distribution companies, broadcasters and merchandizing rights companies. The constellation of core actors changes little during the innovation trajectory, although the intensity of their involvement does change from stage-to-stage. At the start of the production phase, the animation companies recruit a substantial project team, possessing most of the required skills. However, some tasks, such as script and music writing tend to be outsourced to freelance operators. In two cases, the actual animation during the production stage is outsourced to more cost-competitive animation studios. 
Most of the artistic work during the initial development stage is done largely in-house, typically by one or two artists. The main source of knowledge is the embodied knowledge of the artists (developed during previous work and education). Inspiration is obtained from a wide variety of sources. General ideas can come from random sources, including TV programmes, DVDs, the Internet, trade journals, children playing, children's books, computer games, public markets, etc.

You would look at trade journals, TV schedules, you would watch kids playing [...] you would really throw the net wide. [...] For example, when you are in an airport, you would wander into bookshops and see which children's books they stock [...] you would watch kids playing with toys, what are they doing? All these situations give you an impression of current trends in the market. [...] you would even get inspiration from just the computer games or TV shows that you like to watch. It is a lifestyle. (Creative Director, Case 1)

For more specific (to the particular TV series) ideas, the artists rely on many of the same sources, as well as script writers and feedback from the broadcasters and distributors. Knowledge of the audience is largely mediated through the client broadcasters and distributors who know their target audiences and undertake tests.

Know-who type knowledge about external partners is embodied in the core staff of the company. This knowledge is kept up-to-date by visiting international trade fairs and by involvement in projects. External partners, notably the distributors and co-producers, can represent an important additional source of know-who type knowledge. Other, less important sources include online professional networking sites and word-of-mouth between producers.

The success of the innovation depends on skilled and experienced crew. Because most of the crew changes from project-to-project, know-who type knowledge is important for recruitment as well. Much of the knowledge regarding potential candidates is embodied in the firms' core staff developed during involvement in projects and visiting trade fairs. Other recruitment media include online international animation forums and the firms' websites.

The pre-production phase involves many of the same sources of knowledge and inspiration. The network of producers, co-producers, distributors and commissioning clients is now in place. Script writers become the most important external source of ideas. Commissioning clients and broadcasters also provide input, mainly through commenting on the suitability of the material for the target audience, rather than providing original ideas. Co-producing animation companies can become an additional source of ideas and know-how. The temporary crew can become an important source of know-how as well.

The animation companies make relatively little use of external advisors (other than their consortium) as a source of creative knowledge. The only examples are the Internet forums and blogs where artists do post some of their work and receive feedback from other members of the animation community. At the beginning of the production stage, typically, most of the core innovation and knowledge has already been generated. External actors, notably the (contract) animation studios receive instructions but contribute little new knowledge to the project. Finally, where the post-production was done by co-producers, these provided important know-how knowledge. 


\section{Location, Proximity and Buzz in the Animation Industry}

This section examines the relative importance of local and global knowledge flows in knowledge creation and the extent to which different flows are sensitive to proximity. Building on the conceptual discussion in the "Knowledge bases and proximity" section, it starts with an examination of the origin of crew and location of the collaborating partners during the various stages of the innovation trajectory and how location is related to the importance and frequency of the face-to-face mode of knowledge exchange. This is followed, successively, by an analysis of the role of relational proximity in knowledge flow and the salience of "buzz".

\section{Origin of Project Staff and Location of Partners}

As regards temporary and free-lance crew, all companies rely heavily on international recruitment. The crews are truly international, mostly recruited from Europe. Specialized positions for which no suitable candidates could be found are filled with specialists from Canada or the US. For recruitment, the companies rely on ads on animation-specific international recruitment sites or forums and the companies' own websites. More specialized positions were filled partially on the basis of word-of-mouth or the core staff's personal experience of working with individuals and the international Internet forums. There is an Irish blog as well but this is less important.

I mean, today you really can't concentrate on one country. I mean, I have got most of my work from other countries rather than Ireland. It is hard to get jobs in France because they have a lot of super-talented French illustrators but I have worked for companies in China, Germany, the UK and the US. (Art Director, Case 3)

As regards collaborating partners, from the point of view of the focal company, nearly all significant co-producers, main commissioning broadcasting clients, distributors, merchandizing partners, contract animation partners and script writers are located overseas. In Case 2, the focal company has a co-production agreement with an Irish animation company which takes care of the post-production, but the most significant co-producer is located in Canada. In Case 3, clients include an Irish broadcaster, but the more influential broadcaster/distributor is located overseas.

Nearly all of the main partners and clients during the stages dominated by the symbolic mode of knowledge creation are located overseas. These stages involve a great deal of communication. During the initial development phase, most of the creative (artistic) activities are conducted by a very small number of staff in a single company and these activities therefore involve limited communication with external partners. Where external partners are involved, the tacit nature of the knowledge flow and know-how requires a substantial amount of face-to-face contact. Another core activity during this stage is the development of the consortium of project partners (co-producers, broadcasters/commissioners, etc.) and securing the required finance. These activities involve a substantial amount of communication concerning commercial/legal matters and project co-ordination. These negotiations are at least as important a driver for face-to-face meetings. However, the substantial amount of face-to-face contact is satisfactorily organized through frequent shortterm visits, some of which can be organized to coincide with one of the international trade 
fairs. Interestingly, in Case 3, the overseas broadcasting client has never visited the Dublin studio of the focal company. The relationships were built during face-to-face meetings at the international trade events and knowledge flow was facilitated by sustained electronic communication.

During the subsequent (pre-production, production and post-production) stages, the communication intensifies, particularly between the producers, co-producers, animation contracting studies and free-lance script writers. The amount of business-related communication is substantially reduced. However, communication about the actual artistic content and co-ordination intensifies. Creating an animated television series involves the development of designs and multiple takes and retakes of episodes. All this material is going back and forth between the producers, co-producers, contract animation houses and commissioning clients that all need to make comments. Most of this material is transferred electronically, but the process does involve a substantial amount of email and telephone discussions as well. The core directors and producers have at least weekly conference calls and video conferences with the co-producers as well as daily telephone and email contact.

However, the level of face-to-face contact is relatively limited. In two cases, the contact between the production company and the co-producers is limited to an initial "meet-andgreet" and an occasional meeting if major issues arose. Interestingly, the art director of Case 3 prefers electronic communication over face-to-face meetings to communicate aesthetic issues.

I also found, if I have points on screen in front of me or on paper, I can always go back to them, because I think if you speak to somebody face-to-face and you are asking them to change a number of things, a lot of things can be forgotten. (Art Director, Case 3)

In one of the cases, the creative people in the focal company have more intensive faceto-face contact with the co-producer-about four times over the project period-precisely because of the problems with communicating the tacit content.

During the production stage, collaboration with the animation contract studios in the Far East typically required no face-to-face contact other than an initial "meet-and-greet", although two focal companies did station an overseas supervisor to oversee the activities. However, since the knowledge flow involved is of a less tacit nature, his main task is coordinating the scheduling and making sure that deadlines are met.

The final post-production stage is the only stage where the synthetic mode of knowledge creation takes the upper hand. In most cases, this again involves international partners. In Case 3, the post-production activities were conducted in collaboration with an Irish post-production company. This collaboration did involve a substantial amount of face-to-face contact and shoulder-to-shoulder work. However, this was partly driven by the fact that there was no strong division of labour between the focal company and the post-production partner, with the directors and the sound director of the focal company having a strong role in the post-production. The choice for the Irish post-production company was strongly driven by financial/fiscal considerations rather than by geographical proximity considerations.

Overall, the advantages (or requirement) of involving overseas partners far outweigh the potential (communication-related) advantages that working with local partners would 
bring. One of the reasons for the Irish animation companies to work with overseas co-producers lay in the (national and international) fiscal and financial incentives, which this brought to the project. In addition, international partners were selected on the basis of the complementary capabilities/knowledge they could bring to the series and, in case of the contract animation studios, cost-competitiveness.

\section{Distanciated Learning and Relational Proximity}

The above suggests that modern information technology is facilitating the internationalization of innovation projects and distanciated learning in the Irish animation industry. This is not to say that knowledge flow in the distributed teams is unproblematic. In relation to this, the interviews do provide evidence for the role of non-geographical dimensions of proximity - notably social, institutional and cultural-in facilitating knowledge flow and coordination among geographically distanciated actors (Boschma, 2005; Gertler, 2008).

The most obvious instances relate to social proximity. The animation projects include evidence of the importance of trust and friendship to facilitate knowledge exchange and innovation. Important instances of building social proximity include the meetings during trade-fairs. The friendships, forged "over a pint" appear very important for securing contracts and knowledge exchange. In addition, the focal companies have at least one meet-and-greet meeting with nearly all new partners. One of the main functions of these meetings is precisely to build a level of trust.

I think [face-to-face contact] is very important, even just to 'meet and greet.' You need to forge relationships. Then it is not just an anonymous guy on the other end giving you retakes. I think that is important. Other than that, it is also useful to meet just to 'catch up.' (Producer, Case 3)

In one of the projects, the lack of previous experience and trust with one of the new contract animation studios in the Far East, as well as the difficulty of monitoring the contractor from a distance, was a reason to work with an overseas on-site supervisor. Where the focal company worked with studios it could trust, it worked without such an overseas supervisor.

In relation to linguistic proximity, sharing the same language with most of the core partners in the US and Canada greatly facilitated distanciated learning in all projects. The role of institutional proximity can be related to cultural norms and habits. The role of cultural relations between Ireland and North America was apparent. The relevant culture for Irish focal companies is Anglo-American, not necessarily local. Working with partners from the same culture meant that the collaborating partner was familiar with the underlying (AngloAmerican) children's literature. The cultural proximity increases the absorptive capacity of the receiver (Martin \& Moodysson, 2011) and allowed for the communication of context-specific knowledge in the distributed teams. In contrast, we found examples of cultural distance complicating the knowledge exchange between the focal firms and animation contract studios in the Far East. For example, different cultures have different expressions of joy.

There could be all sorts of mistakes [...] say sense of humour. Like people in Korea don't speak English they don't understand things and when you would have something in the script or written down saying [the character] dances of joy with this ... 
Their interpretation of that could be [...] like let's put one hand in the air and walk slowly. So there is huge kind of cultural things as well. So you would have to get all that redone and tell them exactly what you mean. (Executive Producer, Case 1)

Buzz

This section discusses the role of buzz and the relation between proximity and buzz. The case studies show that unintentional knowledge flow and buzz tends to be most relevant for know-who type knowledge. Some inspiration type knowledge flows unintentionally as well when artists get ideas from a range of sources, such as watching TV, DVDs, children's books, watching children play, computer games, etc.

Interestingly, the sites for unintentional knowledge flow through buzz tend to be mainly international and virtual, rather than local. The most important sites for unintentional know-who type knowledge flow are "international" trade fairs and events. A substantial amount of knowledge flow during these events is unplanned or unforeseen. The "local" sites that are potentially conducive to local buzz tend to be attended relatively infrequently and their relevance for know-who type knowledge is limited.

Not really, there are the occasional [local] bits and pieces but not that much [...]. I used to go to everything once upon a time. But now I feel I know what I want to do and I would prefer to go home early, and spend time with the kids. [... I I see a lot of them anyhow at all the international trade markets I attend. [...] It's all the same animation people from Ireland. [Interviewer: So is that international network more important than the local one?] Oh yes, absolutely.

The interviews suggest that an Irish community does exist and that this may stimulate information flow and buzz. However, the most important sites for knowledge flow are international and virtual and only secondarily local. This is clearly illustrated by the formation of business networks in Case 6. First contact with the main co-producers and clients was established during the annual international trade fairs. Interestingly, it was difficult for the company to get time with a local client in Dublin, but during the evenings at an international trade fair, it was easier.

It is hard to get a meeting with them in Dublin. [But] when they are at this [international event] they have got leisure time in the evening and that is when you meet. The Irish tend to kind of club together. The usual stuff you know and you would get to talk to people, you would have a few drinks. You would be relaxed. That is when you start kind of developing a relationship and after that it is kind of easier to get a meeting because they know what you are about you know. (Director Case 3)

Further unintentional know-who type knowledge is mediated by industry journals, Internet forums and blogs, but here too, the foreign sites are far more important than the ones that cater specifically for an Irish audience. In relation to inspiration type knowledge, although some buzz operates on a local scale (for example, watching children, the "inspirational environment" of Dublin), again substantial elements operate on an international/virtual scale. Children are observed everywhere and books, DVDs, TV programmes are nearly exclusively of an international nature. 
These findings suggest that the conceptualization of "global pipelines" vs. "local buzz" (Bathelt et al., 2004) is problematic in capturing the knowledge flows. Asheim et al. (2007) already pointed out that buzz can be transmitted electronically and face-to-face and can be both local and global. In the Irish animation industry, global buzz and virtual buzz are actually more important than local buzz. This is not to say that there is no Irish community and that this community is irrelevant for facilitating information flow. However, the local community buzzes mainly globally, rather than locally.

\section{Conclusion}

This paper assessed the relevance of the knowledge base conceptualization and the relationship between the symbolic knowledge base and the spatiality of knowledge flow in the context of the animation industry in Ireland. In broad terms, the findings provide further support for the applicability of the knowledge base approach (Asheim \& Gertler, 2005; Asheim et al., 2011) and the association of the animation industry with the symbolic knowledge base. In line with Moodysson et al. (2008), the case studies also support the idea that most activities are in practice comprised more than one mode of knowledge creation and that different modes of knowledge creation are present in different stages of the innovation trajectory, with different intensities. The first stages of the innovation trajectory are dominated by the symbolic mode of knowledge creation, although the level of this dominance diminishes with each stage. Arguably, the post-production stage has as many characteristics of a synthetic as a symbolic knowledge base.

The relevance of the knowledge base conceptualization becomes even more evident when we consider the contrast with the biotechnology industry in Ireland (Van Egeraat \& Curran, 2013; Van Egeraat et al., 2009). Innovation projects in the biotechnology sector differ substantially from the ones in the animation industry and have much in common with the analytical knowledge base as outlined by the proponents of the approach. Knowledge creation is clearly characterized by unravelling the mechanisms of human processes (know-why). During the initial stages, the knowledge generating activities are not aimed at developing a new functional system. Research projects typically start with a hypothesis that is subsequently tested in theoretically inspired research experiments. The research experiments are driven by a clear hypothesis, tend to be highly formalized, based on protocols. Knowledge inputs and outputs are highly codified, often written up in journal articles or patents. At the same time, biotech innovation projects include stages where the analytical mode of knowledge creation is less dominant or where the synthetic mode dominates, a finding in line with the study by Moodysson et al. (2008).

Returning to the animation industry, a number of critical reflections deserve consideration. First, individual stages are not necessarily clearly dominated by a single mode of knowledge creation and involve a more equal combination of two modes. Second, "individual" activities can have characteristics of different knowledge bases. This is related to the third point, the fact that the three knowledge bases are not necessarily mutually exclusive. Some of the characteristics of the synthetic knowledge base overlap with, or would not be in contradiction to, those of the symbolic knowledge base. For example, the animation companies produce one-off shows, where the innovation is user centred and tacit knowledge is important. 
As to the link with space, the proponents of the knowledge base conceptualization suggest that the different knowledge bases are characterized by different sensitivities to geographical distance in relation to knowledge flow (Asheim et al., 2007; Gertler, 2008) with industries drawing on the symbolic knowledge base believed to be most sensitive to geographical distance. The findings in relation to the animation industry in Ireland strongly challenge this idea. During the stages dominated by the symbolic mode of knowledge creation, nearly all of the main partners, clients, temporary staff and other sources of knowledge are located overseas. Collaboration with partners involves a substantial amount of communication, including face-to-face. However, modern information technology is facilitating intensive communication in distributed teams and where face-to-face contact is required, it is satisfactorily organized through frequent short-term visits. Overall, the advantages of involving overseas partners (related to complementary capability, cost-competitiveness and taxation/finance) far outweigh the potential communication-related advantages that working with local partners would bring.

This is not to say that knowledge flow in the distributed teams is unproblematic. In relation to this the study finds support for the role of non-geographical dimensions of proximity, notably social and cultural, in facilitating knowledge flow and co-ordination among geographically distanciated actors (Boschma, 2005; Gertler, 2008).

The study finds little support for the role of "local" buzz in knowledge flow. Interestingly, the sites for unintentional knowledge flow through buzz tend to be mainly international and virtual, rather than local. These findings suggest that the conceptualization of "global pipelines" vs. "local buzz" (Bathelt et al., 2004) is problematic in capturing the knowledge flows. Asheim et al. (2007) already pointed out that buzz can be transmitted electronically and face-to-face and can be both local and global. The current study shows that in the Irish animation industry, global buzz and virtual buzz are actually more important than local buzz. This is not to say that there is no Irish community and that this community is irrelevant for facilitating information flow. However, the community tends to meet during the international events, rather than locally - the local community buzzes mainly globally, rather than locally.

These findings are at variance with the findings of Martin and Moodysson (2011) who, in the context of the moving media industry in Southern Sweden, found support for the theoretical link between the symbolic knowledge base and the spatial patterns of knowledge sourcing. This may indicate that the findings are specific to the animation industry as opposed to the creative industries in general. Apart from the difference in the case industry, we suggest that part of the explanation lies in the difference in focus and methodology. The current study traces the knowledge flows in individual innovation projects. Martin and Moodysson (2011) adopt an aggregate approach to analysing the extent and geography of knowledge networks and flows. On the basis of mapping the location of all collaborating partners (in an unidentified period) connected to the firms in the local cluster, they conclude that intra-regional knowledge exchange is dominant. Such aggregates do not inform us about the relative role of local partners for individual innovation projects. Another element of the explanation may lie in the role of cultural proximity. The study shows how, in the Irish case, distanciated learning is facilitated by the affinity of the Irish focal companies with the Anglo-American culture. It is possible that the more localized knowledge flows in the Swedish case are at least partly explained by the fact that many companies in this case are producing for a Swedish or Scandinavian market and that the required cultural affinity is more localized. 


\section{Notes}

1. The following paragraphs draw on Asheim et al. (2011), Asheim et al. (2007) and Gertler (2008).

2. This has been referred to as "temporary geographical proximity" (Torre \& Rallet, 2005), but this term may provide more confusion than clarity. We prefer to interpret this simply as face-to-face contact between geographically distant partners.

3. This paper summarizes the findings of the case studies. For a detailed report of the case studies, see Van Egeraat et al. (2009).

4. An animatic or story reel is a full-length storyboard synchronized with text sound and characters.

\section{References}

Arita, T. \& McCann, P. (2000) Industrial alliances and firm location behaviour: Some evidence from the US semiconductor industry, Applied Economics, 32(11), pp. 1391-1403.

Asheim, B. \& Gertler, M. (2005) The geography of innovation, in: J. Fagerberg, D. Mowery \& R. Nelson (Eds) The Oxford Handbook of Innovation, pp. 291-318 (Oxford: Oxford University Press).

Asheim, B., Coenen, L. \& Vang, J. (2006) Face-to-face, buzz and knowledge bases: Socio-spatial implications for learning innovation and innovation policy, in: L. Coenen (Ed.) Far Away, So Close, pp. 207-234 (Lund: Lund University).

Asheim, B., Coenen, L. \& Vang, J. (2007) Face-to-face, buzz and knowledge bases: Socio-spatial implications for learning, Environment and Planning C, 25(5), pp. 655-670.

Asheim, B., Boschma, R. \& Cooke, P. (2011) Constructing regional advantage: Platform policy based on related variety and differentiated knowledge bases, Regional Studies, 45(7), pp. 893-904.

Bathelt, H., Malmberg, A. \& Maskell, P. (2004) Clusters and knowledge: Local buzz, global pipelines and the process of knowledge creation, Progress in Human Geography, 28(1), pp. 31-56.

Boschma, R. (2005) Proximity and innovation: A critical assessment, Regional Studies, 39(1), pp. 61-74.

Chesbrough, H. (2003) Open Innovation (Boston: Harvard Business School Press).

Gertler, M. (2008) Buzz without being there? Communities of practice in context, in: A. Amin \& J. Roberts (Eds) Community, Economic Creativity and Organisation, pp. 203-226 (Oxford: Oxford University Press).

Gertler, M. S. \& Wolfe, D. A. (2006) Spaces of knowledge flow: Clusters in a global context, in: B. Asheim, P. Cooke \& R. Martin (Eds) Clusters and Regional Development: Critical Reflections and Explorations, pp. 218-236 (London: Routledge).

Hollingsworth, J. R., Schmitter, P. \& Streeck, W. (Eds) (1994) Governing Capitalist Economies: Performance and Control of Economic Sectors (Oxford: Oxford University Press).

Kim, L. \& Nelson, R. (2000) Technology, Learning and Innovation: Experiences of Newly Industrialising Economies (Cambridge: Cambridge University Press).

Kitschelt, H. (1991) Industrial governance structures, innovation strategies and the case of Japan: Sectoral or cross-national comparative analysis? International Organisation, 45(4), pp. 453-493.

Lundvall, B. (1992) National Innovation Systems: Towards a Theory of Innovation and Interactive Learning (London: Pinter).

Lundvall, B., Johnson, B., Andersen, E. \& Dalum, B. (2002) National systems of production, innovation and competence building, Research Policy, 31(2), pp. 213-231.

Malerba, F. (2005) Sectoral systems: How and why innovation differs across sectors, in: J. Fagerberg, D. Mowery \& R. Nelson (Eds) The Oxford Handbook of Innovation, pp. 380-407 (Oxford University Press).

Malmberg, A. \& Maskell, P. (2002) The elusive concept of localization economies: Towards a knowledge-based theory of spatial clustering, Environment and Planning, A, 34(3), pp. 429-449.

Martin, R. \& Moodysson, J. (2011) Innovation in symbolic industries: The geography and organisation of knowledge sourcing, European Planning Studies, 19(7), pp. 1183-1203.

McKinnon, A. (1997) Logistics, peripherality and manufacturing competitiveness, in: B. Fynes \& S. Ennis (Eds) Competing from the Periphery: Core Issues in International Business, pp. 335-369 (Dublin: Oak Tree Press).

Moodysson, J. (2007) Sites and Modes of Knowledge Creation: On the Spatial Organisation of Biotechnology Innovation (Lund: Lund University).

Moodysson, J. (2008) Principles and practices of knowledge creation: On the organization of "Buzz" and "Pipelines" in life science communities, Economic Geography, 84(4), pp. 449-470. 
Moodysson, J., Coenen, L. \& Asheim, B. (2008) Explaining spatial patterns of innovation: Analytical and synthetic modes of knowledge creation in the Medicon Valley life science cluster, Environment and Planning A, 40(5), pp. 1040-1056.

Oerlemans, L. \& Meeus, M. (2005) Do organisational and spatial proximity impact on firm performance? Regional Studies, 39(1), pp. 89-104.

Polanyi, M. (1967) The Tacit Dimension (New York: Anchor Books).

Saxenian, A. (1994) Regional Advantage: Culture and Competition in Silicon Valley and Route 128 (Cambridge, MA: Harvard University Press).

Saxenian, A. (2006) The New Argonauts: Regional Advantage in a Global Economy (Cambridge, MA: Harvard University Press).

Storper, M. (1997) The Regional World: Territorial Development in a Global Economy (London: Guilford).

Storper, M. \& Venables, A. (2004) Buzz: Face-to-face contact and the urban economy, Journal of Economic Geography, 4(4), pp. 351-370.

Torre, A. \& Gilly, J. (2000) On the analytical dimension of proximity dynamics, Regional Studies, 34(2), pp. 169-180.

Torre, A. \& Rallet, A. (2005) Proximity and localization, Regional Studies, 39(1), pp. 47-59.

Van Egeraat, C. \& Curran, D. (2013) Social networks and actual knowledge flow in the Irish biotech industry, European Planning Studies. doi: 10.1080/09654313.2012.761746

Van Egeraat, C. \& Jacobson, D. (2006) The geography of linkages in the Irish and Scottish computer hardware industry: The role of information exchange, Journal of Economic and Social Geography, 97(4), pp. 45-18.

Van Egeraat, C., O'Riain, S. \& Kerr, A. (2009) Social and spatial structures of collaboration and innovation in the Irish biotech and digital media industries. NIRSA Working Paper No. 50, National Institute for Regional and Spatial Analysis, Maynooth.

Yin, R. (2003) Case Study Research: Design and Methods (Thousand Oaks: Sage). 